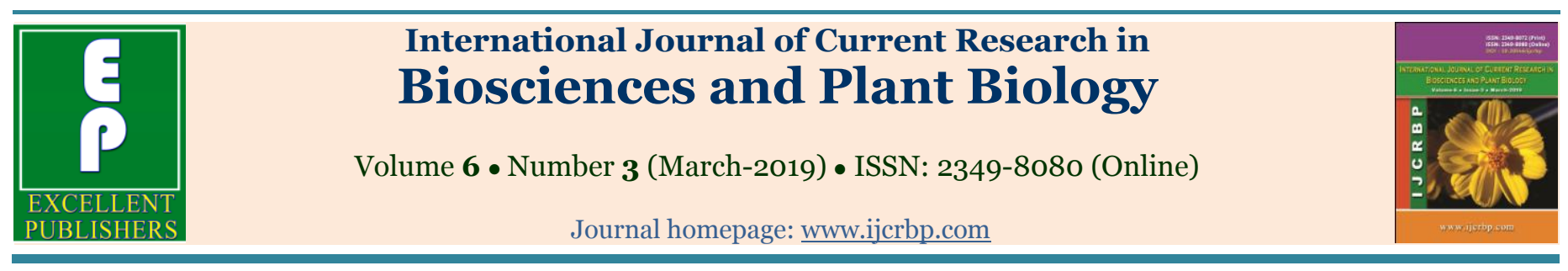

\title{
Effects of exogenous glycine betaine (GB) on cold resistance of Phoebe microphylla
}

\author{
Pujie Wei, Xiongwei Dai, Jiaxin Duan and Bing Sun*
}

Germplasm Resources Evaluation and Innovation Center of Phoebe Yangtze University, Jingzhou-434025, Hubei, China

*Corresponding author; e-mail: 690593440@qq.com

\begin{tabular}{|c|c|}
\hline Article Info & ABSTRACT \\
\hline $\begin{array}{l}\text { Date of Accept } \\
\text { 05 February } 20\end{array}$ & \multirow{4}{*}{$\begin{array}{l}\text { The aim was to study exogenous GB on cold resistance of Phoebe microphylla. Taking } \\
\text { one-year-old Phoebe microphylla seedlings as materials, effects of different } \\
\text { concentrations (50. 100. } 150 \mathrm{mmol} \cdot \mathrm{L}^{-1} \text { ) exogenous GB on cold resistance of Phoebe } \\
\text { microphylla under low temperature. Under low temperature stress, foliar spraying of } \\
\text { different concentrations GB significantly decreased malonaldehyde (MDA) content, } \\
\text { Relative conductivity, and increased chlorophyll, Soluble protein, Soluble sugar, } \\
\text { peroxidase (POD), superoxide dismutase (SOD) activities in Phoebe microphylla. } \\
\text { Among } 3 \text { kinds of GB concentrations, } 150 \mathrm{mmol} \cdot \mathrm{L}^{-1} \mathrm{~GB} \text { was the best for Phoebe } \\
\text { microphylla on cold resistance. A certain concentration GB preprocessing mitigates the } \\
\text { harm of low temperature stress on Phoebe microphylla seedling, and improves their } \\
\text { ability of cold resistance. }\end{array}$} \\
\hline $\begin{array}{l}\text { Date of Publication: } \\
\text { o6 March } 2019\end{array}$ & \\
\hline Keywords & \\
\hline Betai & \\
\hline
\end{tabular}

\section{Introduction}

Phoebe microphylla is a second-class protected tree species in China (Dong, 2016). It is an evergreen tree with straight trunks and beautiful trees. It is both a superior timber species and an excellent greening species. However, temperature has a great influence on the metabolism process in plants, and it also limits their geographical distribution ( $\mathrm{Li}$ et al., 2004). In the cultivation process of Phoebe microphylla, it is highly susceptible to low temperature stress.

Low temperature stress is a common environmental stress factor in plant growth and development. Plants are constrained by environmental temperature from various stages of seed germination, development, fruiting and dormancy, and can interfere with the normal physiology of plants under low temperature stress (Lyons, 1973). The cold resistance of plants is related to various factors, such as variety, plant water content, protective enzymes, cell osmotic pressure, and endogenous hormones. Glycine Betaine (GB), as a kind of compatible substance, is widely distributed in animals, plants and microorganisms (Rhodes et al., 1993). GB is an important non-toxic osmotic regulator in higher plants. Under adversity, the main function of these metabolites is to maintain the water content of cells as osmotic regulators, and effectively protect the structure and function of protein and biofilm, so as to maintain the normal physiological function of cells (Yancey et al., 1982). It has also been confirmed that exogenous GB can improve the tolerance of crops at low 
temperatures to improve their cold resistance (Allard et al., 1998). However, there are few studies on the cold resistance of exogenous GB in Phoebe microphylla. Therefore, this study investigated the changes of cold resistance physiological indexes of leaves of Phoebe microphylla seedlings treated with different concentrations of GB at low temperature, and revealed the effect of GB on the cold resistance of Phoebe microphylla seedlings, which provided a reference for cold resistance research of Phoebe microphylla.

\section{Materials and methods}

\section{Test materials}

Phoebe microphylla was used as the text plant in this experiment. The solid seedlings with good growth condition and the same growth rate were placed in a plastic basin with a diameter of $15 \mathrm{~cm}$ containing a substrate (soil: sand $=1: 1$ ). The transplanted Phoebe microphylla was cultivated in the Bonsai Garden $\left(29^{\circ} 26^{\prime} \mathrm{N} \sim 31{ }^{\circ} 37^{\prime} \mathrm{N}, 111\right.$ ${ }^{\circ} 15^{\prime} \mathrm{E} \sim 114^{\circ} \mathrm{O} 5^{\prime} \mathrm{E}$ ) of the West Campus of Yangtze University, Jingzhou City, Hubei Province. Jingzhou City has a subtropical transitional monsoon climate with an annual average temperature of $15.9^{\circ} \mathrm{C}$ to $16.6^{\circ} \mathrm{C}$, a frost-free period of $242 \mathrm{~d}$ to $263 \mathrm{~d}$, an average annual sunshine duration of $1800 \mathrm{~h}$ to $2000 \mathrm{~h}$, and an annual precipitation of $1100 \mathrm{~mm}$ to $1300 \mathrm{~mm}$. After 4 months of routine management, processing begins.

\section{Test design}

Determination of cold resistance index of seedlings of Phoebe microphylla. According to the experimental design, each test group was fully and evenly sampled, marked and sealed, and stored in an ultra-low temperature refrigerator. The material was sprayed with GB every 7 days, divided into 4 treatments, each treatment was repeated 3 times, treatment 1 was water, treatment 2 was $150 \mathrm{mmol} \cdot \mathrm{L}^{-1} \mathrm{~GB}$, treatment 3 was $100 \mathrm{mmol} \cdot \mathrm{L}^{-1} \mathrm{~GB}$, treatment 4 was $50 \mathrm{mmol} \cdot \mathrm{L}^{-1} \mathrm{~GB}, 3$ seedlings per pot, and treated with water as a control. After 48 hours of treatment, the materials were cultured in artificial intelligence incubators at $\mathrm{O}^{\circ} \mathrm{C},-2.5^{\circ} \mathrm{C}$ and $-5^{\circ} \mathrm{C}$ for 12 hours, then resumed at room temperature for 24 hours, then several mature leaves were taken and stored in liquid nitrogen and then into ultra-low temperature refrigerator at $-84^{\circ} \mathrm{C}$ for the following experiments.

\section{Determination method}

The chlorophyll content was determined by Wang Xuekui method (Wang, 2006); the protein content was determined by Wang Xuekui's Coomassie Brilliant Blue G-250 method (Wang, 2006); The determination of soluble sugar in plant tissue was referred to Wang Xuekui's Anthrone Colorimetric Method (Wang, 2006); Malondialdehyde content was determined by Kramer's method (Kramer et al., 1991); the peroxidase activity was determined by Nickel's method (Nickel et al., 1969)

\section{Data analysis}

SAS 10.0 statistical software and Excel 2003 software were used to process the relevant experimental data. The physiological indexes of one-year-old Phoebe microphylla seedlings after treatment were compared and analyzed by variance analysis and Duncan multiple comparison method.

\section{Results}

\section{Effects of different proportions of GB on chlorophyll of Phoebe microphylla seedlings}

Chlorophyll is an essential pigment for plant photosynthesis, the material basis of photosynthesis, and one of the important indicators to measure plant cold resistance. According to Fig. 1, after spraying GB, the total chlorophyll content of Phoebe microphylla seedlings was significantly affected. In all low temperature treatments, spraying $150 \mathrm{mmol} \cdot \mathrm{L}^{-1}$ GB significantly increased the total chlorophyll content compared with treatment 1 , while the total chlorophyll content in treatment 3 and 4 decreased significantly. At $\mathrm{O}^{\circ} \mathrm{C}$ and $-2.5^{\circ} \mathrm{C}$, the total chlorophyll content of treatment 1 and 4 was not significant, while at $-5^{\circ} \mathrm{C}$, the total chlorophyll content of treatment 1 was significantly lower than the other treatment groups. The experimental data showed that spraying GB at $150 \mathrm{mmol} \cdot \mathrm{L}^{-1}$ concentration could 
effectively increase the total chlorophyll content of Phoebe microphylla leaves, while the chlorophyll content of Phoebe microphylla decreased significantly with the decrease of GB concentration.

\section{Effects of different proportions of GB on soluble protein content of Phoebe microphylla seedlings}

Appropriate increase of soluble protein in plant can alleviate the damage of bad environment to seedlings. The content of soluble protein can measure the adaptability of plant to adversity. According to Fig. 2 , at $\mathrm{O}^{\circ} \mathrm{C}$ and $-2.5^{\circ} \mathrm{C}$, the soluble protein content of the leaves of treatment 2 was significantly increased compared with treatment 1 , while the soluble protein content of treatment 3,4 was significantly decreased, and the difference between treatment 1 and 4 was not significantly; at $-5^{\circ} \mathrm{C}$, the soluble protein content of treatment 2, 3 and 4 increased significantly compared to treatment 1 , and treatment 2 increased most significantly. The results showed that spraying $150 \mathrm{mmol} \cdot \mathrm{L}^{-1}$ of $\mathrm{GB}$ could significantly increase the soluble protein content of Phoebe microphylla leaves, and the effect was most significant at $\mathrm{O}^{\circ} \mathrm{C}$.

\section{Effects of different proportions of GB on soluble sugar content of Phoebe microphylla seedlings}

Soluble sugar is a protective substance in cells under cold and freezing conditions. Under low temperature exercise, its content is positively correlated with the cold resistance of most plants. Plants can resist cold by increasing soluble sugar content in the cold environment. According to Fig. 3, spraying $150 \mathrm{mmol} \cdot \mathrm{L}^{-1}$ of GB significantly increased the soluble sugar content of leaves compared with treatment 1 , while the total content of chlorophyll in treatment 3 and 4 decreased significantly, and there was no significant difference in soluble sugar content between treatment 1 and 4. After analysis, spraying $150 \mathrm{mmol} \cdot \mathrm{L}^{-1}$ of $\mathrm{GB}$ significantly increased the soluble sugar content of Phoebe microphylla leaves, and inhibited the soluble sugar content with the decrease of spraying concentration.

\section{Effects of different proportions of GB on malondialdehyde content of Phoebe microphylla seedlings}

MDA is a product of the peroxidation of unsaturated fatty acids in cell membranes. It has strong cytotoxicity and is one of the important indicators for measuring the damage of membrane system. According to Fig. 4, the malondialdehyde (MDA) content of Phoebe microphylla seedlings increased with the decrease of the concentration of GB sprayed.

At $\mathrm{o}^{\circ} \mathrm{C}$, the MDA content of Phoebe microphylla seedlings treatment 2 was significantly lower than that of treatment 1 , and treatment 3 and 4 were significantly lower than treatment 1 ; At $2.5^{\circ} \mathrm{C}$ and $-5^{\circ} \mathrm{C}$, the MDA content of treatment 2, 3, 4 Phoebe microphylla seedlings was significantly lower than that of treatment 1 , and the MDA content of treatment 2 was significantly lower than that of treatment 3 and 4 . The results showed that the application of GB at a concentration of $150 \mathrm{mmol} \cdot \mathrm{L}^{-1}$ could effectively reduce the MDA content in leaves of Phoebe microphylla.

\section{Effects of different proportions of GB on the electrical conductivity of Phoebe microphylla seedlings}

Plants usually produce reactive oxygen species in low temperature conditions, which initiates membrane lipid peroxidation or alters cell membrane permeability, which in turn affects plant metabolism, resulting in increased relative conductivity.

According to Fig. 5, the electrical conductivity of Phoebe microphylla seedlings increased with the decrease of the concentration of GB sprayed. At $0^{\circ} \mathrm{C},-2.5^{\circ} \mathrm{C}$, and $-5^{\circ} \mathrm{C}$, the electrical conductivity of the treatments 2, 3, 4 Phoebe microphylla seedlings was significantly lower than that of treatment 1 , and the conductivity of treatment 2 was significantly lower than treatment 3 and 4 . The results showed that the application of GB at a concentration of $150 \mathrm{mmol} \cdot \mathrm{L}^{-1}$ could effectively reduce the damage of the Phoebe microphylla leaves. 
Effects of different proportions of GB on the protective enzyme activities of Phoebe microphylla seedlings

POD is an important protective enzyme in plants, which can disproportionate with reactive oxygen species and free radicals. POD is an enzymatic defense system of membrane lipid peroxidation, which can protect cell membranes from damage under low temperature stress. According to Fig. 6, after spraying GB, the POD activity of leaves in treatment 2 was significantly higher than that in treatment 1 at $\mathrm{o}{ }^{\circ} \mathrm{C}$ and $-5^{\circ} \mathrm{C}$, and the difference between treatment 1 and treatment 4 was not significant. At $-2.5^{\circ} \mathrm{C}$, treatment 2 was significantly different from other treatments, and treatment 3 and treatment 4 were not significantly different. The results showed that the POD activity of Phoebe microphylla leaves could be significantly increased when the concentration of GB was $150 \mathrm{mmol} \cdot \mathrm{L}^{-1}$.

\section{Effects of different proportions of GB on superoxide dismutase activity of Phoebe microphylla seedlings}

SOD can scavenge reactive oxygen species in low temperature conditions to maintain cell membrane stability and protect cells from membrane lipid peroxidation. According to Fig. 7, after spraying GB, the SOD activity of Phoebe microphylla leaves in treatment 2 was significantly higher than that of the treatment 1 at $\mathrm{O}^{\circ} \mathrm{C}$, and the difference between treatment 4 and treatment 1 was not significant. At $-2.5^{\circ} \mathrm{C}$ and $-5^{\circ} \mathrm{C}$, treatment 2 was significantly different from other treatments, and treatment 3 and treatment 4 were not significantly different. The results showed that the SOD activity of Phoebe microphylla leaves could be significantly increased when the concentration of GB was 150 $\mathrm{mmol} \cdot \mathrm{L}^{-1}$.

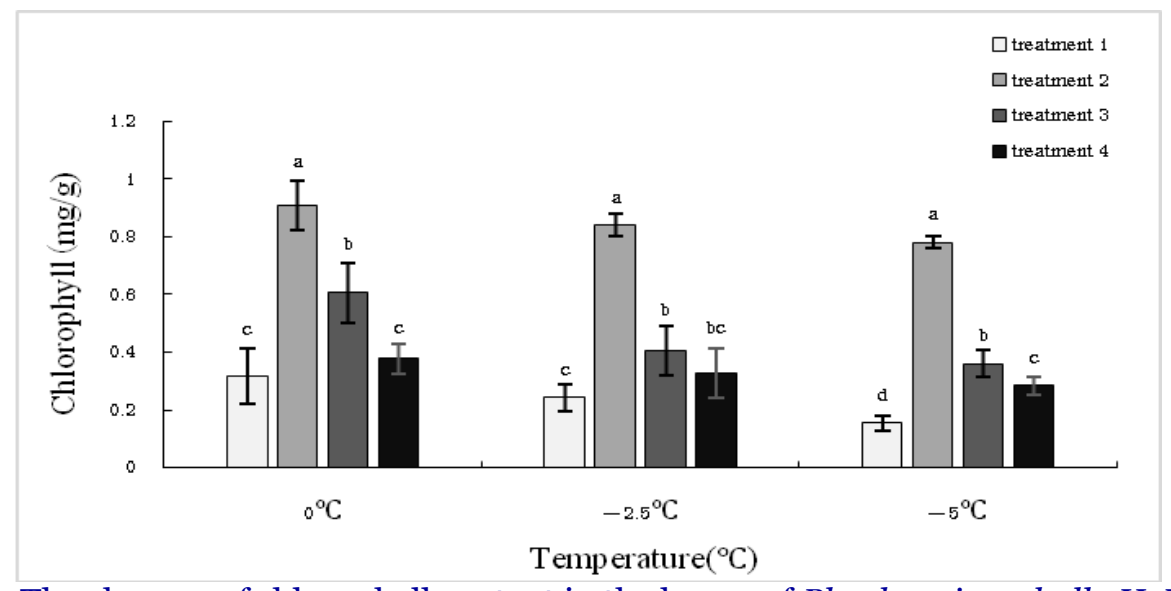

Fig.1 The changes of chlorophyll content in the leaves of Phoebe microphylla $\mathrm{H}$. W. Li

Note: Different lowercase letters in the figure indicate significant differences $(p<0.05)$, the same below.

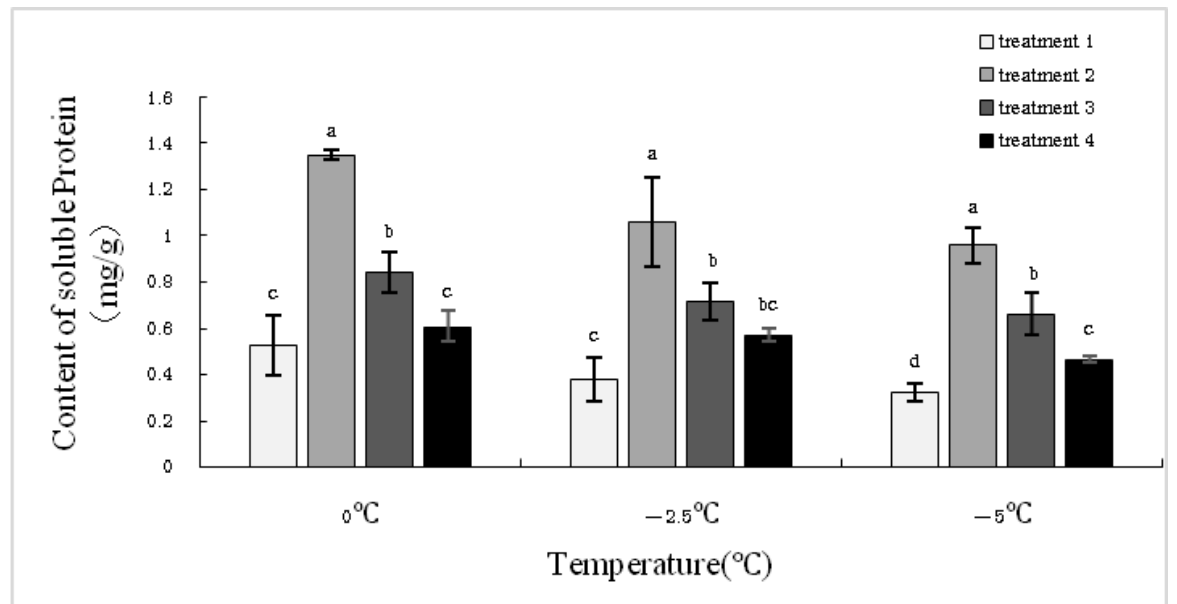

Fig.2: The changes of soluble protein content in the leaves of Phoebe microphylla $\mathrm{H}$. W. Li 


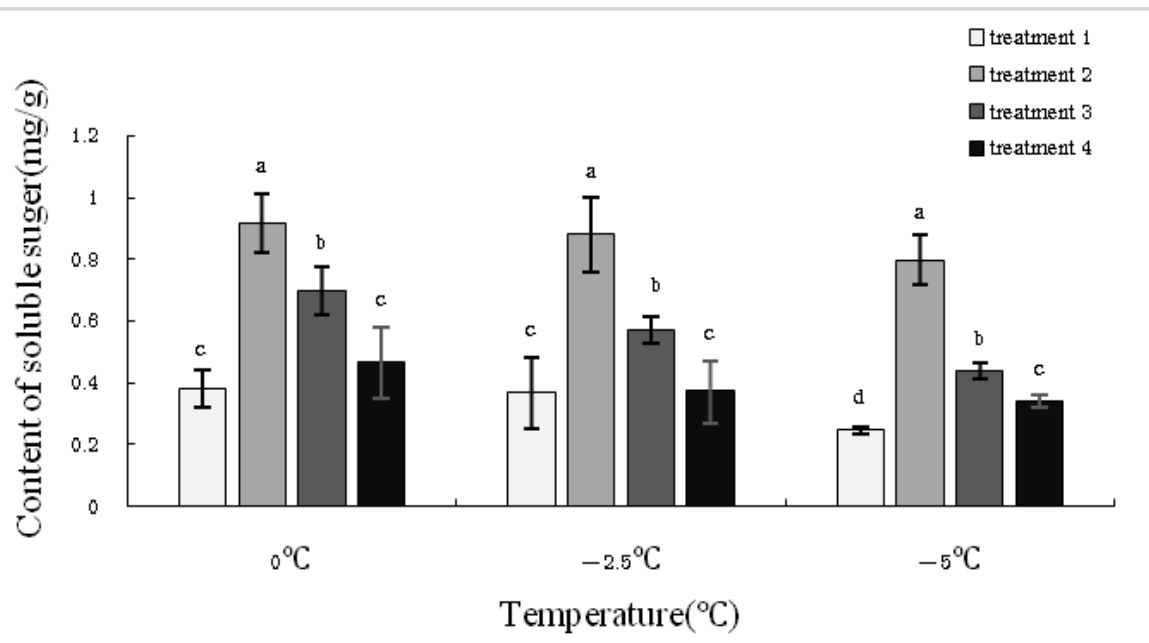

Fig. 3: The changes of soluble sugar content in the leaves of Phoebe microphylla H. W. Li

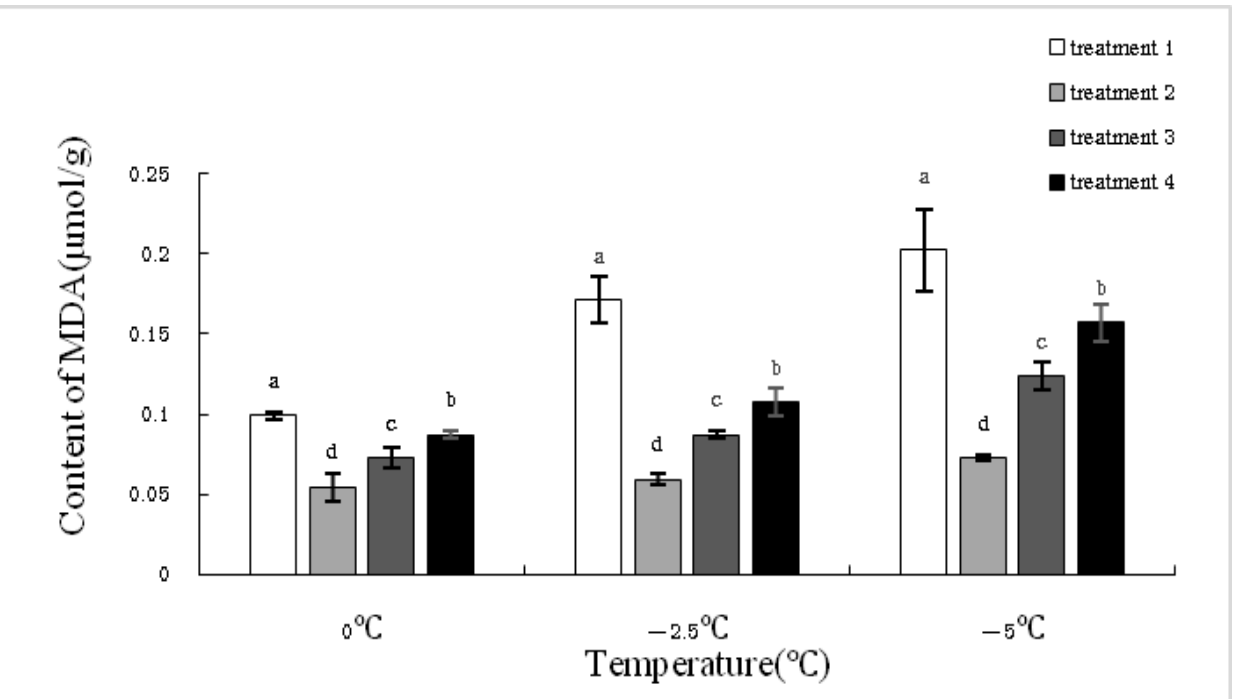

Fig. 4: The changes of malondialdehyde content in the leaves of Phoebe microphylla H. W. Li

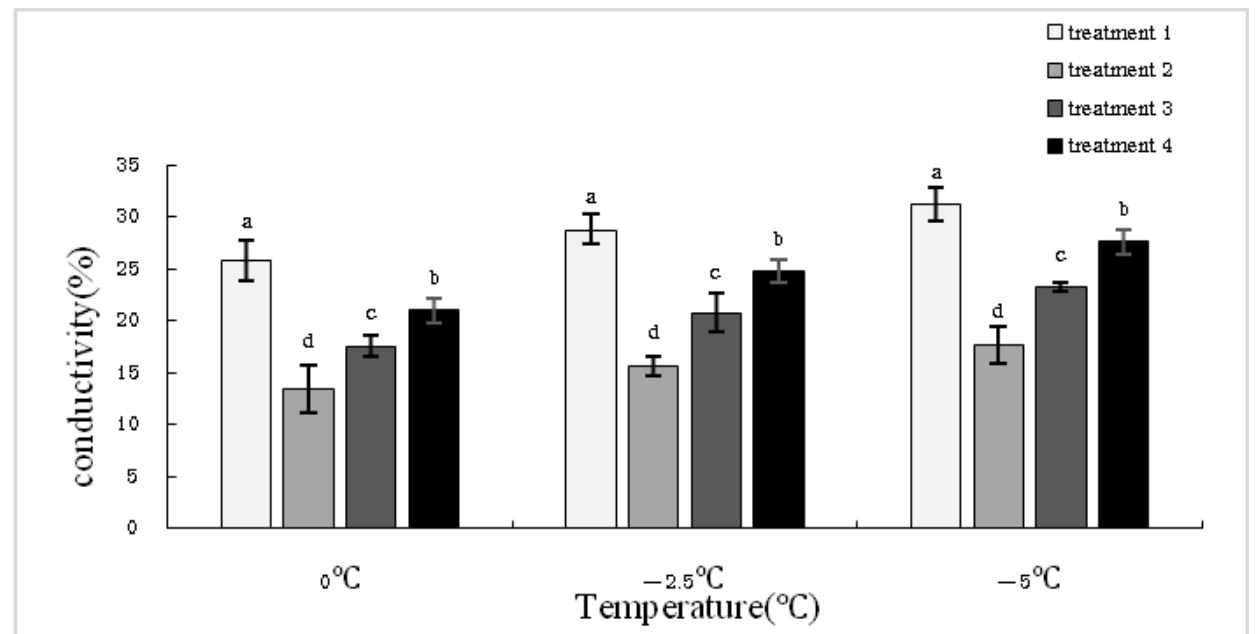

Fig. 5: The changes of conductivity in the leaves of Phoebe microphylla H. W. Li 


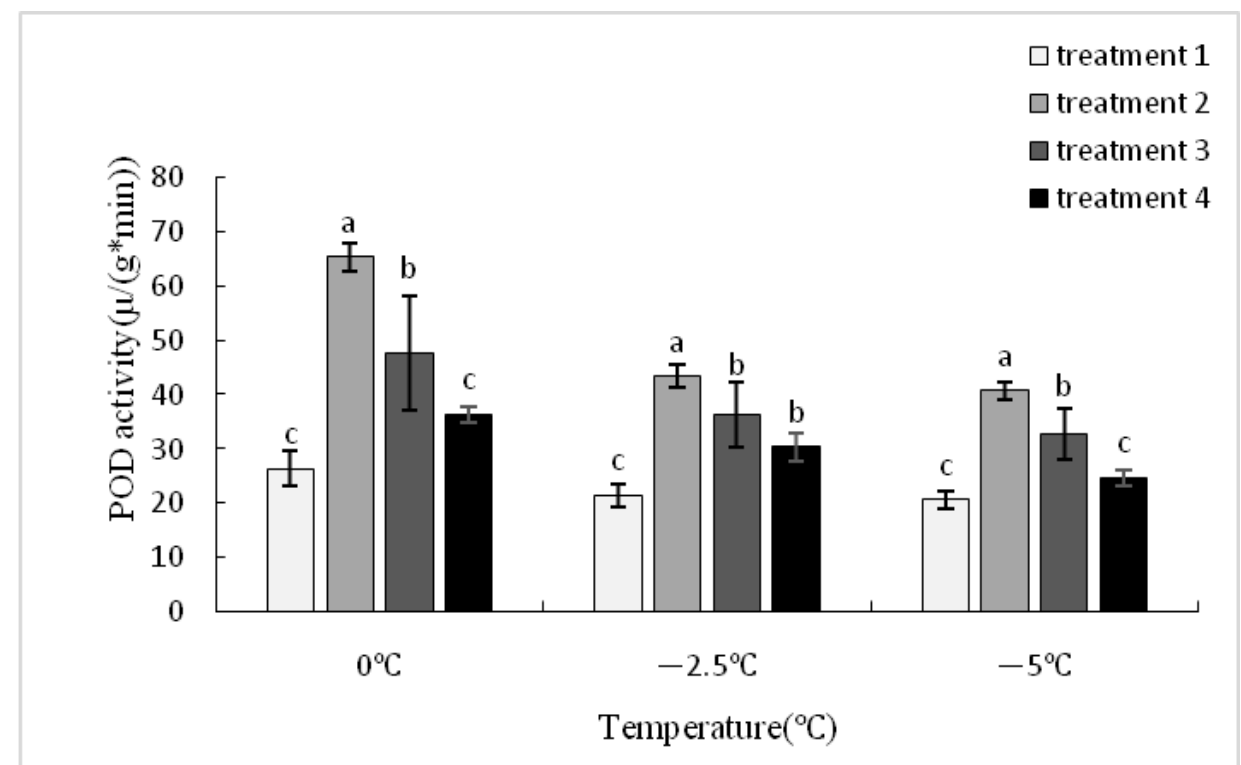

Fig. 6: The changes of POD activity in the leaves Phoebe microphylla H. W. Li

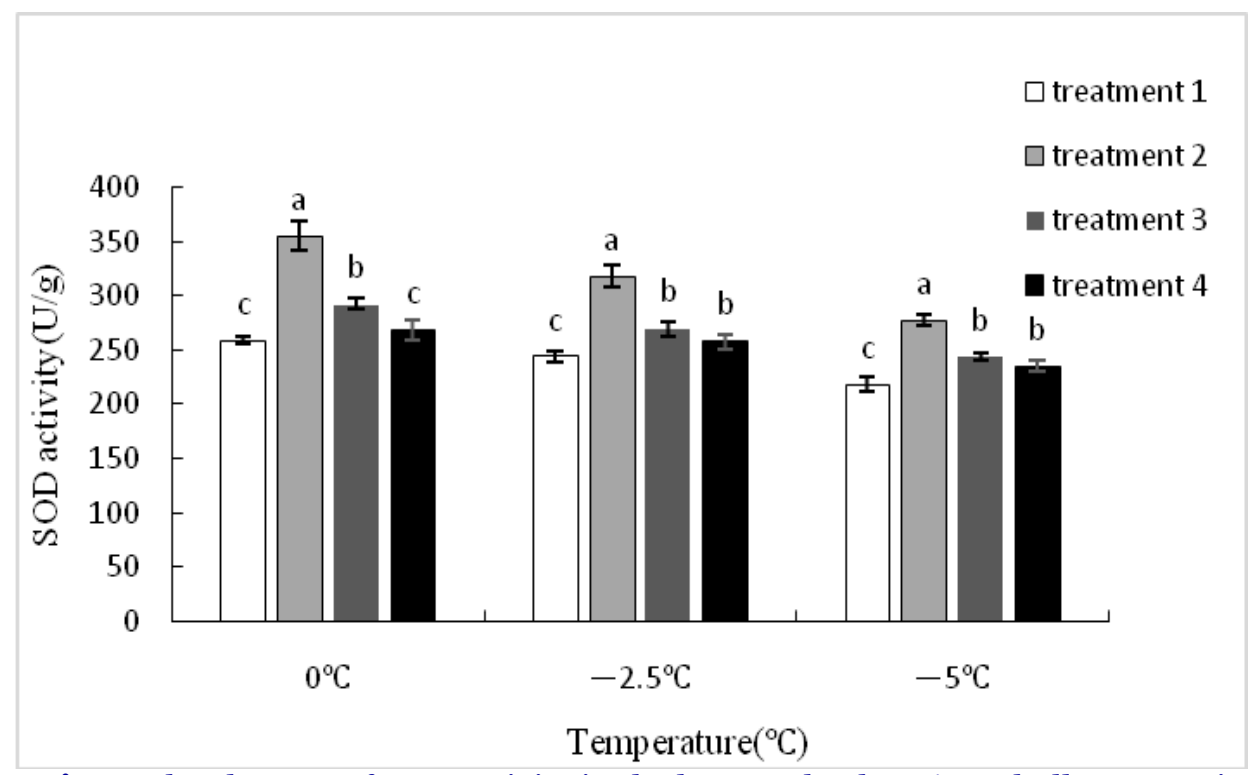

Fig.7: The changes of SOD activity in the leaves Phoebe microphylla H. W. Li

\section{Discussion}

Chlorophyll is the key pigment of plant photosynthesis, the material basis of photosynthesis and the photosensitizer of photosynthesis (Allen et al., 2001). Photosynthetic organs are cold sensitive parts of plants, and low temperature directly affects the performance and activity of photosynthetic apparatus (Liu et al., 2007). When the GB was sprayed, the chlorophyll content of Phoebe microphylla leaves increased, which indicated that the suitable concentration of exogenous GB could protect the structure and function of chlorophyll, which is similar to the research conclusion of Chen Wenchao (Chen et al., 2011).

Soluble protein is a protective substance of plant tissues. When the content of soluble protein increases, its water-holding capacity is enhanced to avoid dehydration damage of protoplasm at low temperature (Gao et al., 2010). Low temperature can activate a large number of resistance genes and promote the synthesis of cold-resistant 
proteins (Liu et al., 1993). Soluble sugar accumulation is closely related to the concentration of plant cell fluid. The accumulation of sugar in vacuole can reduce the cytoplasmic freezing point and improve the cold resistance of plants (Liang et al., 2015), and soluble sugar has a maintenance effect on mitochondria and membrane coupling factors (Kuang et al., 2017). After spraying the appropriate concentration of GB, the content of soluble protein and soluble sugar increased significantly, which were consistent with previous results (Li et al., 2007).

When plants are subjected to low temperature stress, reactive oxygen species can cause peroxidation of membrane lipids. MDA is the end product of lipid membrane peroxidation, and its content can reflect the degree of damage of biofilms (Lin et al., 2012). Wang Hua et al. (Wang et al.,2000)showed that the content of MDA in plants reflects the strength of cold resistance, and there are negatively correlated. After spraying the appropriate concentration of GB, the MDA of the leaves of Phoebe microphylla decreased significantly, and the studies of Ma Zanliu (Ma et al., 2012) and Li Maofu (Li et al., 2008) obtained similar conclusions. Relative conductivity is one of the important parameters to measure the level of damage that a plant's somatic cell membrane system suffers under conditions of adversity. Under stress, the general electrolyte permeability was positively correlated with the degree of stress in plants (Guo et al., 2006). In addition, GB can alleviate cell membrane damage and solute extravasation, inhibit relative conductivity and enhance cell membrane stability, which is similar to the conclusion reached by $\mathrm{Li}$ Yang ( $\mathrm{Li}$ et al.,2015). The results showed that $150 \mathrm{mmol} \cdot \mathrm{L}^{-1}$ of GB could effectively alleviate the damage of plants caused by stress, significantly reduce the accumulation of MDA of cell membrane peroxidation, reduce cell membrane damage, prevent electrolyte extravasation, and reduce the damage rate of leaves. It was of great significance to improve the cold resistance of Phoebe microphylla. SOD and POD, as one of the physiological and biochemical indicators related to cold resistance in plants, are the main protective enzyme system of plants under stress conditions, which can promote the cold resistance of plants ( $\mathrm{Li}$ et al., 2015).

\section{Conclusions}

The results of this study indicate that the spraying of a certain concentration of GB can increase the activity of SOD and POD in leaves of Phoebe microphylla, and effectively eliminate the unfavorable damage caused by low temperature stress, which is similar to the results of Ma Zanliu (Ma et al., 2012). In summary, the application of different concentrations of GB can significantly change the various physiological and biochemical indexes of Phoebe microphylla leaves, thereby improving the cold resistance of the plants. But different concentrations of GB had different effects on the cold resistance of Phoebe microphylla, and the optimum concentration for improving the cold resistance of Phoebe microphylla was $150 \mathrm{mmol} \cdot \mathrm{L}^{-1}$ GB.

\section{Conflict of interest statement}

Authors declare that they have no conflict of interest.

\section{Acknowledgement}

This work was supported by the national second survey for key protected wild plant resources (special investigation for Phoebe and Machilus in Hubei Province), the Science and Technology Support Program in Hubei Province of P. R. China (2013BBB24), the Natural Science Foundation Project in Hubei Province of P. R. China (2014CFB264, 2017CFB390), National Natural Science Foundation (31270740), Guidance Project of Hubei Education Department (B20154444).

\section{References}

Allard, F., Houde, M., Kröl, M., 1998. GB improves freezing tolerance in wheat. J. Plant Cell Physiol. 39(11), 1194 - 1202.

Allen, D. J., 2001. Impacts of chilling temperatures on photosynthesis in warm-climate plants. J. Trends Plant Sci. 6(1), 36-42.

Chen, W. C., Yang, B. Z., Zhou, S. D., 2011. Effects of different inducers on cold resistance physiological characteristics of Capsicum annuum. J. Hunan Agric. Univ. 37(4), 396399.

Dong, Y. J., 2016. Effects of different fertilizers on the growth and physiological characteristics of 
Phoebe microphylla seedlings. D. Guangxi Univ.

Gao, J.C., Wang, H.X., Li, X.X., 2010. Study on the relationship between soluble protein and malondialdehyde content and cold resistance of Ziziphus jujube branches. J. Northern Horticult. 23, 18-20.

Guo, S.Z., Deng, C.Y., Zhang, G.J., 2006. Effects of low temperature on the permeability of cell membrane in leaf blade of two cultivars of Jasmimum sambac. J. Chin. J. Eco-Agric. 14(1), 42-44.

Kramer, G. F., Norman, H. A., Krizek, D. T., 1991. Influence of UV-B radiation on polyamines, lipid peroxidation and membrane lipids in cucumber. J. Phytochem. 30(7), 2101-2108.

Kuang, H.L., Yu, F., Du, D., 2017. Study on cold resistance of different concentrations of $\mathrm{CaCl}_{2}$ to seedlings of Machilus ichangensis. J. Hubei Forestry Sci. Technol. 6, 14-19.

Li, D.L., Jin, Y.Q., Xiang, Q.B., 2004. Geographical distribution, research status and development and utilization prospects of Phoebe Nees plant resources in China. J. Fujian Forestry Sci. Technol. 1, 5-9.

Li, M.F., Li, S.P., Lu, Y.L., 2007. Synergistic effect of GB and chitosan on Musa nana seedling's cold resistance. J. Guangdong Agric. Sci. 9, 2528.

Li, M.F., Li, X.C., Li, S.P., 2008. Effects of chitosan and glycine $\mathrm{GB}$ on cold resistance of Musa nana seedlings under low temperature stress. J. Guangdong Agric. Sci. 11, 20-22.

Li, Y., Dong, R., Liu, Z.M., 2015. Effects of GB on cold tolerance related indexes of Cucumis sativus seedlings under low temperature stress. J. Jiangsu Agric. Sci. 43(11), 217-219.

Liang, S. X., Meng, Q. X., Shi, M. J., 2015. Research on relationship between coldresistance and soluble protein and sugar of Corylus heterophylla $\times$ Corylus avellana branches. J. Chin. Agric. Sci. Bull. 31(13), 14-18.

Lin, Y., Guo, W.Z., Xu, Z.H., 2012.Cold resistance and changes on MDA and soluble sugar of leaves of Ligustrun lucidum Ait. in winter. J. Chin. Agric. Sci. Bull. 28(25), 68-72.

Liu, H.Y., Zhu, Z.J., Shi, Q.H., 2007. Effects of low temperature stress on characteristics of photosynthesis in leaves of own-rooted and grafted Citrullus lanatus seedling. J. Shi Hezi Univ. 25(2), 163-167.

Liu, Z. Q., ABA/Gas., 1993. Emptying specific proteins and cold resistance of Citrus reticulata. J. Horticult. 20(4), 335-340.

Lyons, J. M., 1973. Chilling injury in plants. Ann. Rev. Plant Physiol. J. 24, 445-466.

Ma, Z. L., Song, J., Li, J. J., 2012. Effects of Exogenous glycine GB on cold resistance of Trachelospermum jasminoides Flame and T. jasminoides (Lindl.) Lem. 40(2), 678-679.

Nickel, K. S., Cunningham, B. A., 1969. Improved peroxidase assay method using leuco 2,3',6trichloroindophenol and application to comparative measurements of peroxidatic catalysis. J. Anal. Biochem. 27(2), 292-299.

Rhodes, D., Hanson, A. D., 1993. Quaternary ammonium and tertiary sulfonium compounds in higher plants. Ann. Rev. Plant Physiol. Plant Mol. Biol. 44(1), 357-384.

Wang, H., Wang, F., Chen, D. W., 2000. Effects of low temperature stress on SOD activity and membrane lipid peroxidation in Armeniaca vulgaris flower. J. Fruit Tree Sci. 17(3), 197-201.

Wang, X.K., 2006. Principles and techniques of plant physiological and biochemical experiments. M. (Version 2). Beijing: Higher Education Press.

Yancey, P., Clark, M., Hand, S., 1982. Living with water stress: evolution of osmolyte systems. J. Science. 217(4566), 1214-1222.

\section{How to cite this article:}

Wei, P., Dai, X., Duan, J., Sun, B., 2019. Effects of exogenous glycine betaine (GB) on cold resistance of Phoebe microphylla. Int. J. Curr. Res. Biosci. Plant Biol. 6(3), 23-30.

doi: https://doi.org/10.20546/ijcrbp.2019.603.004 